\title{
Study on the roof-pillar rheological collapse of goaf based on H-K model
}

\author{
Haitao Ma ${ }^{1,2,3, a}$, Hongguang $\mathrm{Ji}^{1, \mathrm{~b}}$, Min Zhang ${ }^{1, \mathrm{c}}$ \\ ${ }^{1}$ School of Civil and Environmental Engineering, University of Science and Technology Beijing, \\ Xueyuan Road, No.30, Haidian Distract, Beijing,China \\ ${ }^{2}$ China Academy of Safety Science \& Technology, Building A1, NO.32 Beiyuan Road, Chaoyang District, \\ Beijing China \\ ${ }^{3}$ Key Laboratory on Mining Goaf Disaster Prevention of SAWS, China \\ a Maht@chinasafety.ac.cn, b jihongguang@ces.ustb.edu.cn, c1786554486@qq.com
}

\begin{abstract}
Key words: goaf collapse; rheological of Pillars; failure in roof; three elements $\mathrm{H}-\mathrm{K}$ model; monitoring in roof.

Abstract. The existing time could be years or even decades for goafs formed in mining. The rheological property of pillars may cause tensile failure in roof, and finally induce goaf catastrophic accidents which put serious threats to people underground and buildings on ground. Previous studies on goaf safety involving time effect are not much, and have some defects. This paper take three elements $\mathrm{H}-\mathrm{K}$ model as the constitutive model of rock, considers the time effect, and makes an analysis for the whole process of deforming and failure in roof caused by rheological deformation of pillars. Through a reasonably dividing to the whole process of failure in roof and analysis, the function relationship between roof breakage and time was obtained. Achievements of this paper are expected to provide a new idea for mining goaf safety evaluation.
\end{abstract}

\section{Introduction}

It's a long time since the related researches about the failure in roof of goafs begins. The scholar of China, Qian M. G(2003) ${ }^{[1]}$ proposed the "masonry beam" model in 1982, founded the mechanic model where the roof strata was viewed as elastic plate. Most of the later related researches are based on this simplifying assumption. Based on this theory, the failure condition of roof could also be solved out in elastic mechanics. Researches in recent years has showed that, the stability of goaf is not a single problem of collapse or not. The length of stable time is also with great meaning. The rheological property of rock could affect a lot to the stress and strain state. And a reasonable estimating on how long the goaf could stay stable on itself and when to take measures on the prevention of goaf collapse are necesssary. Researches on the constitutive model of rock material developed from Maxwell model(2002) ${ }^{[2]}$, Kelvin model to combinative forms which could comprehensively reflect the stress and strain characteristics of rock material, such as the three parameter H-K model, Burgers model, Poynting-Thompson model, visco-elastoplastic $\operatorname{model}(2011)^{[3]}$ and so on. The development of elastic mechanics $(1992)^{[4]}$ has provided a way to solve the state of roof and pillars. Other related theories based on some assumptions such as the Winkler elastic foundation beam theory $(2008)^{[5]}$ make a new way out on simplifing the goaf on a large scale. With those theories, it's feasible to simplify the whole goaf into a model built on some assumptions and solve its stress and strain state and failure condition.

For the time effect of the stability of goaf, there are studies from scholars in the past, but the most of these studies are not deep and comprehensive enough. Based on Voronoi theory, Qiu. $\mathrm{F}(2014)^{[6]}$ made a study on the time pillars fail and the final form of goaf in Xianglushan tungsten 
mine. But considering the time effect, they citied the research by West Virginia University, the function relationship between time and pillar strength is not derived analytically, but concluded from a lot of experimental data. Seeing pillars as burgers model, Sun. Q(2014) ${ }^{[7]}$ and Yu. G. $\mathrm{B}(2013)^{[8]}$ made an analytical study on the creeping property of pillars, but all the unknown coefficients were not calculated, conclusions mainly focused on the trend stress and strain changed, and monitoring data only last for days or months, which could not explain the trend goaf changes in existing time of years or decades, that made the conclusions in that paper limited. Xiong. L. $\mathrm{X}(2009)^{[9]}$ built a new constitutive model of rock material based on Burgers model by replace the linear damper to nonlinear. Through experimental studies, it is found that the new constitutive model fits better than Burgers in describing the rheological property of hard rock material. Using Kelvin-Winkler elastic foundation beam model, Li. D. Z(2010) ${ }^{[10]}$ divided the process of roof failure into two stages. The failure condition and existing time were calculated out. Rationality of all those analysis conclusions were verified and proved in engineering examples. But Kelvin model doesn't take the initial elastic of rock material into consideration, and couldn't express the property of rock accurately.

In a word, past researches on the time effect of goaf stability and its stable time estimating have achieved great goals, but there's still shortcomings needed to be solved:

(1)Studies on the rheological property of rock material is still limited, and the development on constitutive model is still in a lack. There's still no constitutive model that reflects the properties of rock accurately.

(2)Existing time of most goaf could reach years or even decades, there's difficulties in monitoring for such a long time. It is necessary for new research methods to test the theoretical results.

(3)Suitable constitutive model is needed which could both consider the actual properties of rock material and meet the demand of theoretical calculation.

\section{Description of the problem}

Among those constitutive models that reflect the time effect of rock deformation, Kelvin model is the most basic and primitive one. Kelvin model is made up by a spring and damper in parallel connection. The constitutive model and creeping curve are shown as Fig.1(a). Kelvin model only takes the time effect of rock deformation into consideration, but without the initial plastic deforming property, which is differ from the actual properties of rock material. On the basis of Kelvin model, Burgers model is the most applied model in goaf stability researches. Burgers model is made up by Kelvin and Maxwell model in series connection. It reflects significant properties of rock material including the initial plastic deforming, time effect and stable creeping, its constitutive model and creeping curve are shown as Fig.1(b). There are too much units in Burgers model, which brings too many unknown parameters that will make the calculation complicated. Based on reasons above, H-K model reflects the time effect and the initial plastic during the rock deformation. By different functions based on the changing of boundary condition during calculation, the steady creeping behavior of rock could be expressed. Constitutive model and creeping curve of $\mathrm{H}-\mathrm{K}$ model are shown as Fig.1(c). 


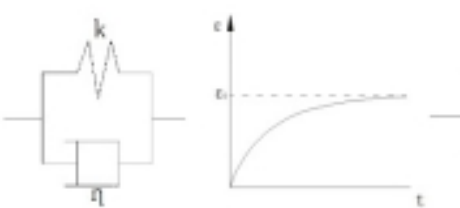

(a)

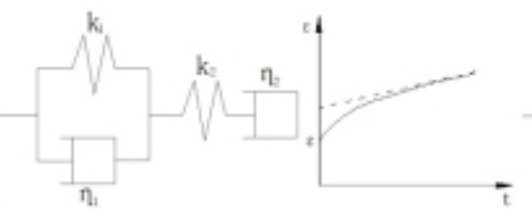

(b)

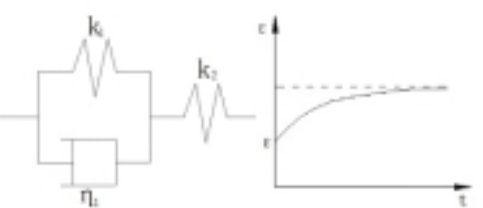

(c)

Fig. 1 constitutive models and their creeping curve

The basic steps of the theoretical study and numerical simulation are as follows:

(1)Solving the controlling equation of roof subsiding. By combining the controlling equation in elastic mechanism and constitutive equation of $\mathrm{H}-\mathrm{K}$ model, an equation in ordinary differential form could be worked out. Its solution refers to the description of the subsiding process of the roof.

(2)By solving the limited condition for roof failure with elastic mechanism, the whole process of roof subsiding and failure could be divided into three stages. Each stage has its corresponding subsiding function. Then the subsidence of roof could be linked with time.

(3)A goaf collapsing case is used to test the whether the calculative solution is right or not. By comparing the goaf collapsing time to the theoretical results, it's easy to see if theoretical solutions are reasonable.

(4)Numerical simulation. A simulation with FLAC3D(Fast Lagrangian Analysis of Continua) is conducted to analyze the whole process of roof subsiding and the development of the goaf collapsing. In the numerical simulation, the changing of subsiding velocity of monitoring point in different place is considered to reflect the goaf collapsing process and its characteristics well. Besides, as an significant factor affecting the goaf stability, the importance of the designation of safety pillars and a reasonable mining plan are also discussed in this paper.

\section{Methodology}

Establishment of the theoretical roof-pillars creeping model and its solution.

(a) Boundary failure condition for the roof.

For the roof, which is assumed as a thin elastic plate under uniformly distributed load, a coordinate could be set in it, as shown in Fig.2.

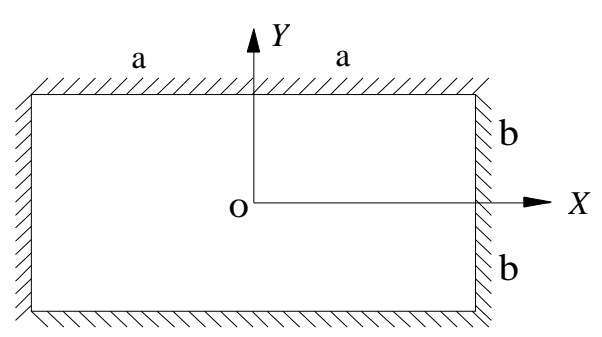

Fig.2 Coordinate setted in roof

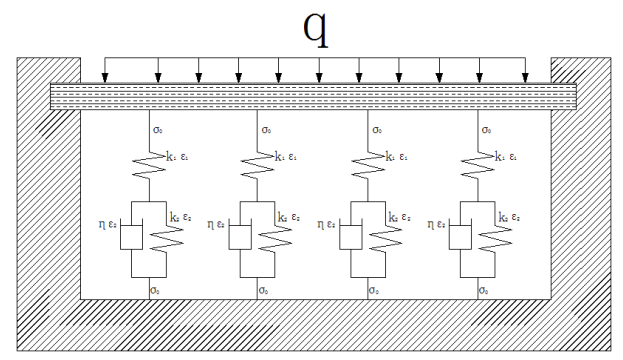

Fig.3 Foundation model with pillars of H-K model

Boundary condition of roof is important because it determines the stable state of the roof. Distribution of stress and strain of roof is affected a lot by the boundary condition. In this paper, the boundary condition is divided into three stages: all hinged, two hinged and two free, all free. Failure conditions of the roof based on elastic mechanics could be written as: 


$$
\sigma_{x \max }=\frac{6\left|\mathrm{M}_{\mathrm{x}}\right|_{\max }}{h^{2}}=\frac{48 D_{w 0}(\mathrm{t})}{a^{2} h^{2}} \geq\left[\sigma_{s}\right] \quad \sigma_{y \max }=\frac{6\left|\mathrm{M}_{\mathrm{y}}\right| \max }{h^{2}}=\frac{48 D_{w 0}(\mathrm{t})}{b^{2} h^{2}} \geq\left[\sigma_{s}\right]
$$

Limited inner failure condition are:

$$
\sigma_{x \max }=\frac{6\left|\mathrm{M}_{\mathrm{x}}\right| \max }{h^{2}}=\frac{3 D \pi^{2}}{2 h^{2}}\left(\frac{1}{a^{2}}+\frac{\mathrm{v}}{b^{2}}\right) w(\mathrm{t}) \geq\left[\sigma_{s}\right], \sigma_{y \max }=\frac{6\left|\mathrm{M}_{\mathrm{y}}\right| \max }{h^{2}}=\frac{3 D \pi^{2}}{2 h^{2}}\left(\frac{1}{b^{2}}+\frac{\mathrm{v}}{a^{2}}\right) \mathrm{w}_{0}(\mathrm{t}) \geq\left[\sigma_{s}\right]
$$

$w_{0}(\mathrm{t})$ refers to the largest inner subsidence, $\mathrm{mm}$;

$\left[\sigma_{s}\right]$ refers to the tensile strength of rock, MPa.

(b) Solve the roof subsiding function

For the H-K model, the constrain of elements of the model should meet

$$
\varepsilon=\varepsilon_{1}+\varepsilon_{2}
$$

The constitutive and creep equations of $\mathrm{H}-\mathrm{K}$ model is

$$
\sigma+\frac{\eta}{k_{1}+k_{2}} \dot{\sigma}=\frac{\eta}{k_{1} k_{2}} \varepsilon+\frac{k \eta}{k_{1}+k_{2}} \dot{\varepsilon}, \varepsilon=\frac{\sigma_{0}}{k_{1}}+\frac{\sigma_{0}}{k_{2}}\left(1-e^{-\frac{k_{2}}{\eta} t}\right)
$$

The relationship between the strain and deformation of pillar is:

$\omega=\varepsilon H$

$\mathrm{H}$ refers to the height of pillar, meters.

An assumption is made that pillars are $\mathrm{H}-\mathrm{K}$ models with the same mechanical parameters(as shown in Fig. 3), and that all the pillars are in uniform distribution. The stiffness of springs in series and parallel connection in the $\mathrm{H}-\mathrm{K}$ model are given as $k_{1}$ and $k_{2}$ respectively, and the damping of damper is given as $\eta$.

The controlling equation of roof could be written as [11](2012):

$$
D \nabla w+\zeta \sigma=q
$$

D refers to the binding stiffness of the roof, $D=\frac{E h^{3}}{12\left(1-\mathrm{v}^{2}\right)}, v$ is the Poisson's ratio. $\zeta$ refers to the ratio of roof area divided by the total sectional area of pillar group.

Take the constitutive equation of $\mathrm{H}-\mathrm{K}$ model (Eq. 1) and equation of strain and deformation (Eq. 2 ) into the roof controlling equation, and Eq. 3 was got.

$$
\begin{aligned}
& D \nabla^{4}\left(w+\frac{\eta}{k_{1}+k_{2}} \dot{w}\right)+\frac{\zeta}{H}\left(\frac{k_{1} k_{2}}{k_{1}+k_{2}} w+\frac{k \eta}{k_{1}+k_{2}} \dot{w}\right)=q \\
& \text { If } \frac{\eta}{k_{1}+k_{2}}=\alpha_{1}, \frac{k_{1} k_{2}}{k_{1}+k_{2}}=\alpha_{2}, \frac{k \eta}{k_{1}+k_{2}}=\alpha_{3}, \text { Equation above could be written as: } \\
& D \nabla^{4}\left(w+\alpha_{1} \dot{w}\right)+\frac{\zeta}{H}\left(\alpha_{2} w+\alpha_{3} \dot{w}\right)=q
\end{aligned}
$$

Set a coordination in the roof, as shown in Fig. 4. If the distribution of roof subsidence could be expressed by function $w(\mathrm{x}, \mathrm{y}, \mathrm{t})=\mathrm{w}_{0}(\mathrm{t}) \varphi(\mathrm{x}, \mathrm{y}) \cdot \varphi(\mathrm{x}, \mathrm{y})$ is the shape function of the subsidence distribution.

The University of Science and Technology Beijing(Wang. J. A. 2010) ${ }^{[12]}$ once took Burgers 
model as the constitutive model of rock, and solved the Galerkin form of the equation (4). In this paper, H-K model was used to take the place of Burgers. Solve the Galerkin form of the equation

(4) and get the ordinary differential form: $\dot{w}_{0}+b_{1} w_{0}+b_{2}=0$

And its solution: $w_{0}=c e^{-b_{1} t}-\frac{b_{2}}{b_{1}}$.

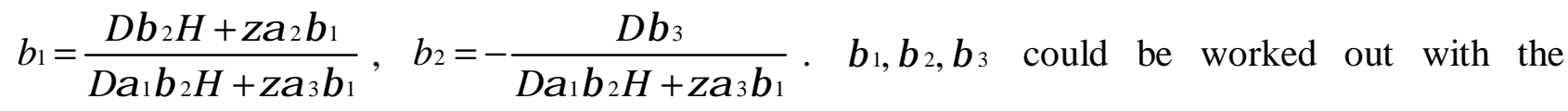
overburden strata stress $q$ and the shape function of roof subsidence distribution $\varphi(\mathrm{x}, \mathrm{y})$. $\beta_{1}=\iint \varphi_{2} d x d y, \beta_{2}=\iint \nabla^{4} \varphi \bullet \varphi d x d y, \beta_{3}=q \iint \varphi d x d y$. In different stage of the roof subsiding, $\beta_{1}, \beta_{2}, \beta_{3}$ changes with different shape function.

(c) Corresponding coefficients of different stages.

For different boundary conditions, the distribution of subsidence changes, stress and strain will change with it. As a result, subsiding function of the roof would change into a new form.

In stage one, the boundary of the roof is hinged. The shape function could be written as:

$\varphi(x, y)=\frac{\left(x^{2}-a^{2}\right)^{2}\left(y^{2}-b^{2}\right)^{2}}{a^{4} b^{4}}$, Corresponding integral coefficients are

$\beta_{1}=\iint \varphi^{2} d x d y=\frac{16384}{99225} a b, \beta_{2}=\iint \nabla^{4} \varphi \bullet \varphi d x d y=\frac{65536}{11025} \frac{1}{a b}+\frac{24576}{4725}\left(\frac{b}{a^{3}}+\frac{a}{b^{3}}\right), \beta_{3}=q \iint \varphi d x d y=\frac{64}{225} a b q$

In stage two, the two long sides of roof failed, boundary condition there changes into simply-supported, while that of short sides remain hinged. Shape function is:

$$
\begin{aligned}
& \varphi(x, y)=\frac{\left(x^{2}-a^{2}\right)^{2}}{a^{4}} \cos \frac{\pi y}{2 b} \text {, And the integral coefficients are } \\
& \beta_{1}=\iint \varphi^{2} d x d y=\frac{128}{730} a b, \beta_{2}=\iint \nabla^{4} \varphi \bullet \varphi d x d y=\frac{32 b}{5 a^{3}}+\frac{32 \pi}{105 a b}+\frac{4 a \pi^{4}}{315 b^{3}}, \beta_{3}=q \iint \varphi d x d y=\frac{16}{15 \pi a b q}
\end{aligned}
$$

In stage three, all sides of the roof change into simply-supported, the subsiding of the roof will cause inner failure. the shape function is: $\varphi(x, y)=\cos \frac{\pi x}{2 a} \cos \frac{\pi y}{2 b}$, Integral coefficients are:

$$
\beta_{1}=\iint \varphi^{2} d x d y=\frac{a b}{4}, \beta_{2}=\iint \nabla^{4} \varphi \bullet \varphi d x d y=\frac{b \pi^{4}}{64 a^{3}}+\frac{\pi^{4}}{32 a b}+\frac{a \pi^{4}}{64 b^{3}}, \beta_{3}=q \iint \varphi d x d y=\frac{4}{\pi^{2}} a b q
$$

From the calculations above, it's clear that the curve of roof subsiding could be divided into three convergent curves. The roof subsiding curve is shown in Fig. 4. 

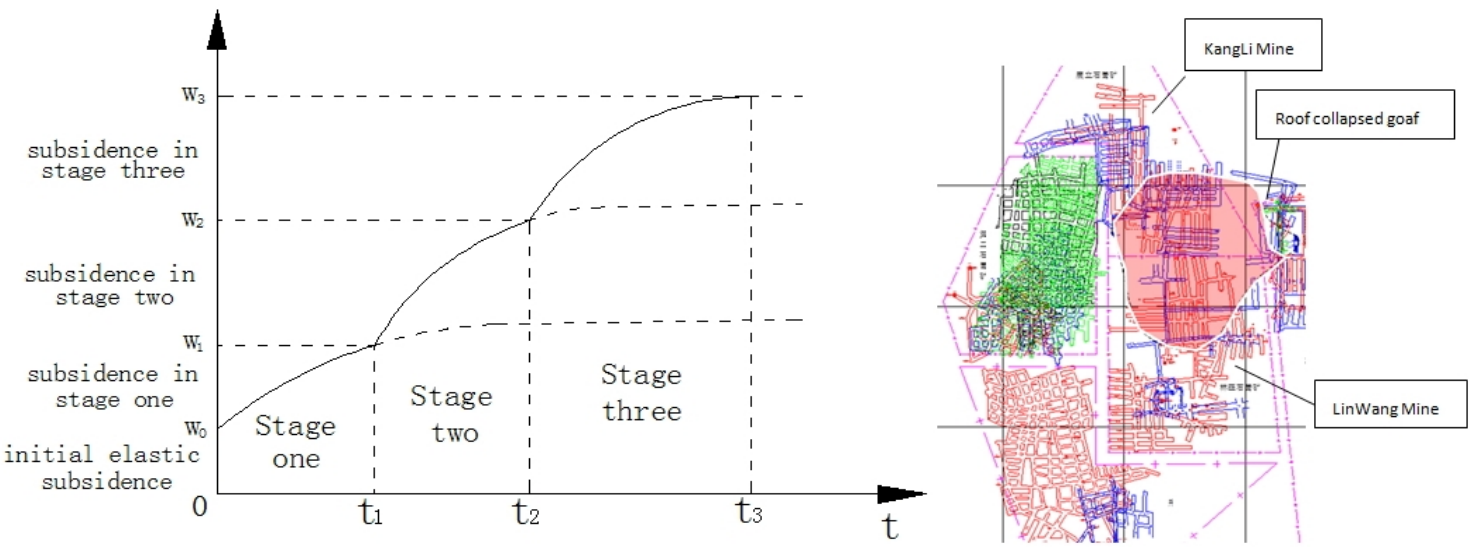

Fig. 4 Roof subsiding curve in the whole process Fig.5 picture of the mine and the collapsed goaf

In this paper, the gypsum mine in Shangwang town, Xingtai county, Hebei province is taken as an example. The mine was built between 1984 and 1998, including five mines, Kang Li, Lin Wang, Tai Hang, Xing Yan, the second gypsum mine. The overlying Quaternary System strata below the surface of mine area is 145 meters thick. The roof is limestone, with a thickness of 38 meters. Properties of all strata are shown in table 1. A particularly significant collapse accident occurred in November 6, 2005 in this mine, caused 37 deaths, 88 houses collapsed, serious cracking deformation in 8 shafts, and a direct economic loss of 7.74 million. The first and second level of Kangli mine, the first and second level of Lin Wang mine, as well as part of Tai Hang mine, the third level of the second mine were included in the goaf collapse. The mine and the collapsed goaf is as shown in fig. 5. Take the collapsed goaf as a rectangular area approximately, the size of roof is $2 a=280$ meters long, $2 b=180$ meters wide. The ratio that roof area divided by total sectional area of pillar group, namely the uniform stress coefficient, which is $\zeta=39.16 \%$. The pillar's height are 8 meters, and the rheological coefficient of pillar's is $\eta=6.41 \times 10^{8} \mathrm{MPa} \cdot h$.

Table 1 Main mechanical parameters of the rock

\begin{tabular}{lllllll}
\hline strata & $\begin{array}{l}\text { Elastic } \\
\text { modulus/MPa }\end{array}$ & $\begin{array}{l}\text { Poisson's } \\
\text { ratio }\end{array}$ & $\begin{array}{l}\text { Bulk } \\
\text { density } /(\mathrm{KN} \cdot \mathrm{m}-3)\end{array}$ & Cohesion/MPa & $\begin{array}{l}\text { Friction } \\
\left.\text { angle/ } /{ }^{\circ}\right)\end{array}$ & $\begin{array}{l}\text { Tensile } \\
\text { strength/MPa }\end{array}$ \\
\hline $\begin{array}{l}\text { Topsoil } \\
\text { Quaternary }\end{array}$ & 50 & 0.30 & 18 & 0.08 & 20 & 0.05 \\
$\begin{array}{l}\text { System Strata } \\
\text { Limestone }\end{array}$ & 500 & 0.23 & 21 & 0.32 & 21.5 & 0.26 \\
Gypsum & 50000 & 0.25 & 24 & 8.40 & 40 & 4.70 \\
\hline
\end{tabular}

The elastic coefficient of the pillar is $k=\zeta \frac{E}{H}=0.3916 \times \frac{7000}{8}=343 \mathrm{MPa} / \mathrm{m}$. The elastic coefficients of the two springs in $\mathrm{H}-\mathrm{K}$ model are $\mathrm{k}_{1}=381 \mathrm{MPa} / \mathrm{m}, \mathrm{k}_{2}=381 \mathrm{MPa} / \mathrm{m}$.

As shown in table 2 are solutions.

Table 2 Calculation of pillar-roof rheological collapse

\begin{tabular}{|c|c|c|c|c|c|c|c|c|c|c|}
\hline Subsidestage & $\mathrm{K}(\mathrm{MPa} \mathrm{m})$ & $\begin{array}{l}\text { Binding } \\
\text { stiffnes5M } \\
\text { Parm3 }\end{array}$ & $\begin{array}{l}\text { Oveburden } \\
\text { stress } \mathrm{MPa}\end{array}$ & $\begin{array}{l}\text { Long sides faihre } \\
\text { subsidence } m m\end{array}$ & $\begin{array}{l}\text { Short sides faihre } \\
\text { subsidence } \mathrm{mm}\end{array}$ & $\underset{\text { subsidence } \mathrm{mm}}{\text { Immer }}$ faihre & $b_{1}$ & $b_{2}$ & $\begin{array}{l}\text { Subsiding } \\
\text { expression } / m \text { m }\end{array}$ & $\begin{array}{l}\text { Failure } \\
\text { timeyear }\end{array}$ \\
\hline $\begin{array}{l}\text { Sta } \\
\text { ge one }\end{array}$ & & & & 5 & & & $352 \times 1$ & $\begin{array}{l}12 \\
1 \times 1 \\
0^{-5}\end{array}$ & $\begin{array}{l}w_{1}=34.55- \\
33.59 e^{-453010^{4}}\end{array}$ & 4.22 \\
\hline Stage two & $\mathrm{k}_{\mathrm{i}}=381 \mathrm{k}=381$ & 228.63 & 3957 & & 12.1 & & $0_{0-5}^{193 \times 1}$ & $\begin{array}{l}20 \\
8 \times 1 \\
0=7\end{array}$ & $\begin{array}{l}w-107.87- \\
102.87 e^{-}\end{array}$ & 4.23 \\
\hline Stage three & & & & & & 245 & $\begin{array}{l}807 \times 1 \\
0^{*} 7\end{array}$ & $\begin{array}{l}16 \\
5 \times 1 \\
06\end{array}$ & $\begin{array}{l}w_{\mathrm{z}}=204- \\
191.9 e^{\mathrm{s}}\end{array}$ & 7.48 \\
\hline
\end{tabular}

From the calculation, the stable time of the goaf is $t=t_{1}+t_{2}+t_{3}=15.93$ years theoretically. From the establishment in 1984 to 2005 when accident took place, the actual stable time is $\mathrm{t}=21$ years. As 
the rheological effect wasn't obvious because the exposed area of the roof wasn't large in the beginning, results in this paper match with the actual situation well.

\section{Numerical simulation study}

To study the changing process of the roof subsidence and the stress of Shangwangzhuang gypsum mine, this paper did a numerical simulation with the finite difference software Flac3D. With a length and width of 1000 meters, and height of 400 meters, the model has 133855 unites and 176992 grids, as shown in Fig.6.

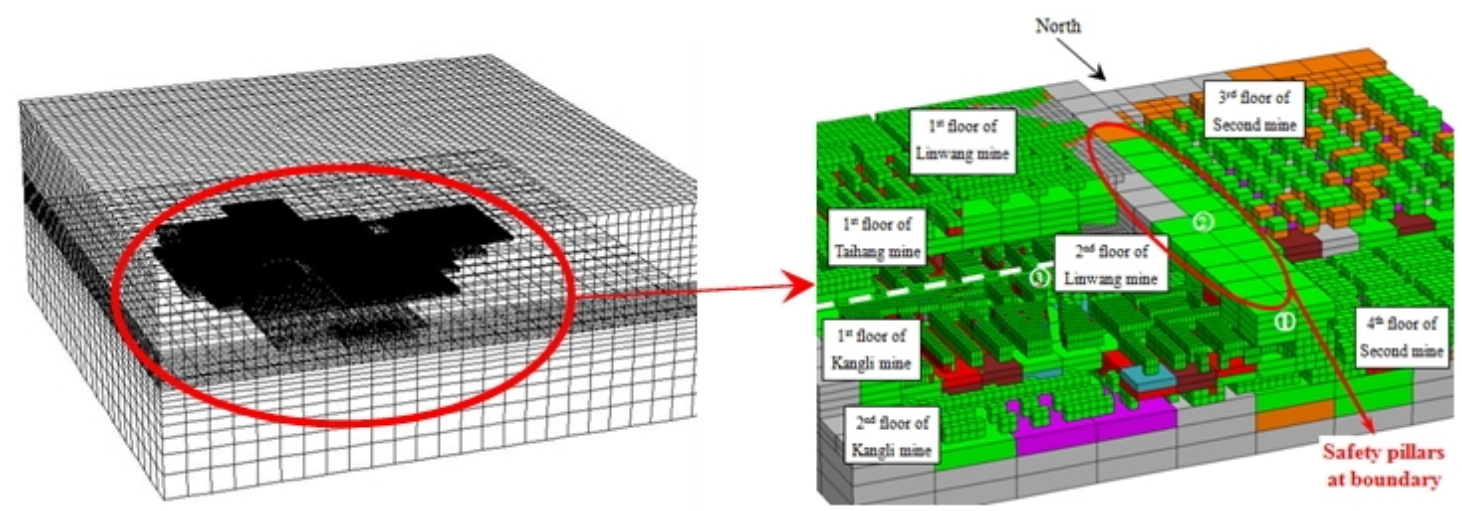

Fig. 6 three dimensional numerical simulation model

Simulate the stable situation of pillars and roof after the goaf formed. Most of the safety pillars in the boundary of mine get yield, maximal main stress reaches $9 \mathrm{MPa}$, which means the strength of safety pillars at the boundary of mine remain high, and the vertical displacement is almost zero. Terrible failure occurs at the northwest of Kangli mine, area (1), with vertical displacement of 6 meters. Less pillar is left between Linwang and Kangli mine, and the size of most pillars are not enough. It could be concluded from the final result, that in area (3), vertical displacement of pillars reaches $7 \mathrm{~m}$, and maximal main stress less than $2.5 \mathrm{MPa}$, which means pillars in this area are all collapsed. The collapsed are in simulation generally align with that in actual, which proved that the high credibility of this numerical simulation.

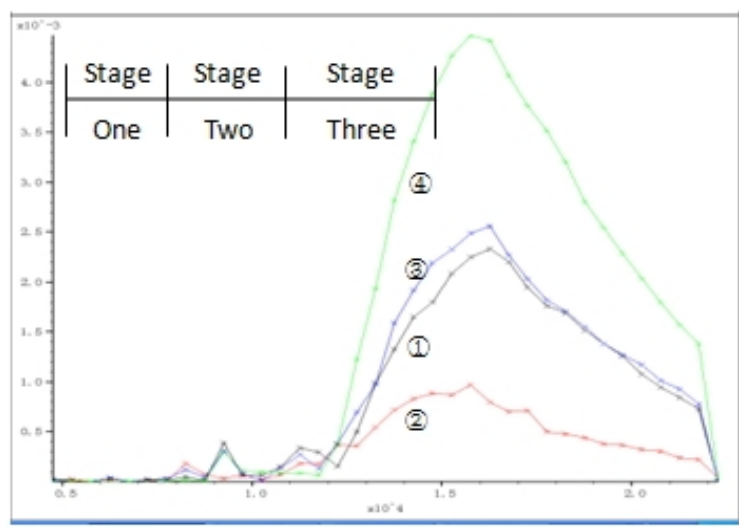

(4) $224 \mathrm{~m}$ below the subsiding centre, roof of Kangli mine

(5) Subsiding centre on ground

(1) pithead of the Kangli main shaft

8) pithead of the Linwang main shaft

Fig.7 Velocity curves of monitoring points 

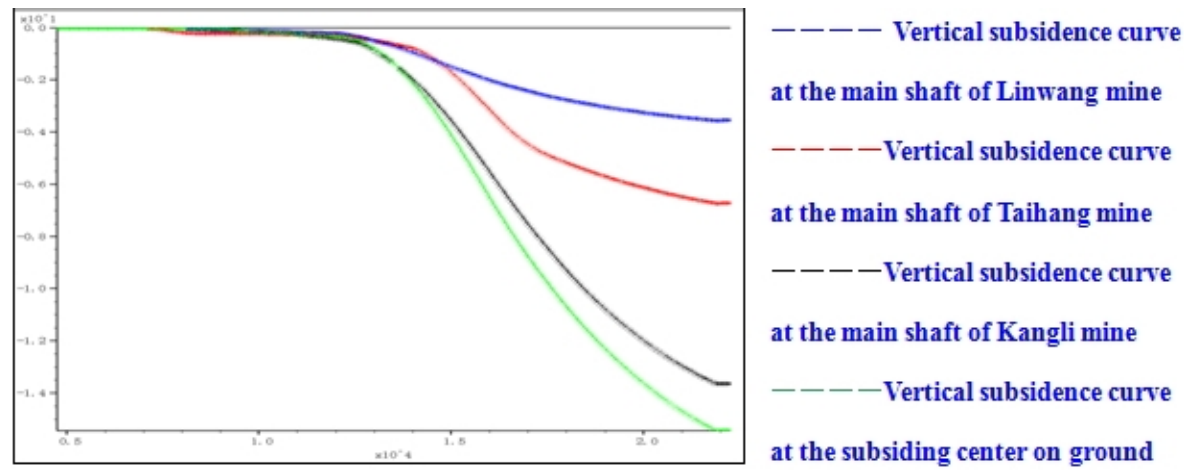

Fig. 8 Subsidence curves of monitoring points

By setting monitoring points, vertical displacement curves in different places of mine and the corresponding subsidence curves was obtained, as shown in Fig.7 and Fig. 8, Curves in simulation was compared with theoretical results.

Shown as the velocity curves of monitoring points, the subsidence of different places in the model doesn't develop steady, stages do exist during the whole subsiding process. It's hard to identify how long each stage is. But by comparing the time steps in simulation with the theoretical time of each stage, it can be found that the ratio of steps each stage takes in the simulation matches well with the time in actual case, which proves that theoretical solutions in this paper is credible.

Safety pillars were designed at the boundary of Kangli and Taihang mines in the plan. During the mining work later, the Kangli mine transferred its eastern to Taihang mine, which made the safety pillars mined off. With the lack of safety pillars, floors and roofs of the two mines open to each other, which made the area collapsed goaf twice in the simulation.

Fig. 9 shows the collapsed area if safety pillars were mined off or not. It's clear to see that the maximum of vertical displacement, showing with the color of blue, mainly occurs among the roof of the southern of Kangli mine and northern of Linwang mine if safety pillars weren't mined off. Taihang mine is not affected by the collapse because of the safety pillars at the boundary.
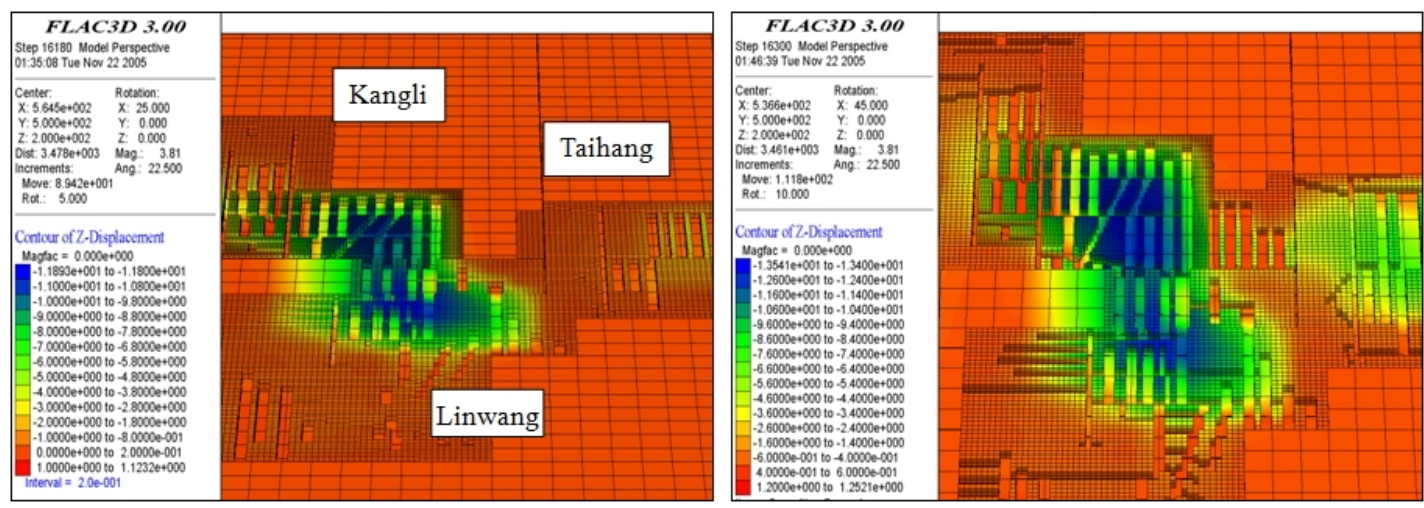

Fig.9 Vertical displacement if safety pillars were mined off

Once the safety pillars between Kangli and Linwang mines were mined off, most of the two mines are involved into the collapsed area, even Taihang mine are affected by this badly collapse.

By analyzing the subsiding velocity of roof in different period and the existing time of goaf, it is possible to estimate which subsiding stage the roof is in, then assessment for the goaf stability could be made out. 


\section{Results}

Theoretically, the subsiding curve of the pillars-roof creeping system in H-K constitutive model should convergent in the end. But in actual cases, affected by the boundary condition, the subsiding curve enters into the next stage before it tends to convergent obviously, which makes the subsiding curve of roof solved by $\mathrm{H}-\mathrm{K}$ model familiar with that by Burgers. But, on the other hand, unknown parameters involved into solving in the H-K calculation, only one initial condition is needed in solving the functions in each stage. In the study on Shangwangzhuang gypsum mine, subsiding function of each stage is:

Stage one: $w_{1}=34.55-33.59 e^{-3.52 t \times 10^{-6}} \mathrm{~mm}$

Stage two: $w_{2}=107.87-102.87 e^{-1.93 \times 10^{-6}} \mathrm{~mm}$

Stage three: $w_{3}=204-191.9 e^{-8.07 t \times 10^{-7}} \mathrm{~mm}$

From the beginning of mining in Shangwangzhuang gypsum mine, it has been 21 years until the final goaf collapse. The stable time in the solution based on $\mathrm{H}-\mathrm{K}$ model is about 16 years. As the exposed area of roof is small at the beginning, and the creeping is slow, the results in this paper is credible.

\section{Conclusion}

(1) Compared with the previous studies on goaf rheological system with Burgers and Kelvin model, $\mathrm{H}-\mathrm{K}$ model takes rock initial elastic and rheological properties into consideration, and could reflect the actual property of rock better than Kelvin model. Less unknown parameters involved in the analytical process, which make formulas easier to solve than that in Burgers model.

(2) The process of the roof subsiding is periodical, it's necessary to take account for both the goaf existing time and variation tendency of subsidence to estimate that in which stage roof is. Meanwhile, mining plan and process is also important while assessing the stability of goaf. In the case in this paper, besides the creeping property of pillars which enlarged the danger of roof failure, there were also defections in the design of mining plan and safety pillars left during mining, which led to the occurrence of the goaf catastrophe.

(3) For studies on goaf stability and the estimating of stable time, as it may be years or even decades from the goaf formed to its collapsing, the numerical simulation is a good way to conduct the study and verify. Although the time steps in simulation doesn't equal to real time, it can still reflect some characteristics during the subsiding of roof and the collapse of goaf.

(4) The process of calculation is based on the theory of elasticity mechanics in this paper, assuming that rock mass is homogeneous and isotropic, and didn't consider the effect of weather, joint and underground water. For studies on the influence of those factors, correlated coefficients should be reducted.

\section{References}

[1] Qian. M. G., Shi. P. W: Mining Pressure Inducing and Strata Control (China University of Mining and Technology Press, Xuzhou 2003).

[2] Cai. M. F., He. M. C., Liu. D. Y: Rock Mechanics and Engineering (Science Press, Beijing 2002).

[3] Li. Q., Xu. H., Bu. W. K., et al.. An analytic solution describing the visco-elastic deformation of coal pillars in room and pillar mine. Mining Science and Technology(China), Vol. 21. (2011), p. 885-890. 
[4] Xu. Z. L: Theory of Elasticity (High Education Press, Beijing 1992).

[5] Li. S. Q., Zheng. G. Analytic Solution of Beams on Winkler Foundation Under Complex Conditions. Chinese Journal of Geotechnical Engineering, Vol. 33. (2008), p. 873-879.

[6] Qiu. F., Ma. H. T., Ouyang. M., et al. Prediction of Pillar Instability Based on Voronoi Chart and Time Effect. Journal of Safety Science and Technology, Vol. 10.(2014), p. 38-43.

[7] Sun. Q., Wei. X. G., Wei. X., et al. Study on Effects of Pillars Rheological Properties on Open-pit Slope Stability. China Safety Science Journal, Vol. 24.(2014), p. 85-91.

[8] Yu. G. B., Yang. P., Chen. Z. C. Study on Surrounding Rock Stability of Pillar Extraction in Thin Gently Inclined Ore Body. Journal of China Coal Society, Vol. 38.(2013), p. 294-298.

[9] Xiong. L. X., Yang. L. D., Zhang. Y. Non-stationary Burgers model for rock. Journal of Central South University Science and Technology, Vol. 41.(2010), p. 679-684.

[10] Li. D. Z. Study on the Stability of Mined-out Goaf and Its Safety Evaluation. University of Science and Technology Beijing. (2009).

[11] Ma. H. T., Wang. J. A., Wang. Y. H. Study on Mechanics and Domino Effect of Large-scale Goaf Cave-in. Safety Science, supp(50). (2012), p. 689-694.

[12] Wang. J. A., Li. D. Z., Ma. H. T. Study of Rheological Mechanical Model of Pillar-roof System in Mined-out Area. Chinese Journal of Rock Mechanics and Engineering, Vol. 29.(2010), p. 577-582. 